\title{
Valor nutritivo de gramíneas do gênero Cynodon consorciadas com amendoim forrageiro
}

[Nutritive value of grasses of genus Cynodon mixed with forage peanut]

\author{
A.B. Fioreli ${ }^{1}$, M.F. Ziech ${ }^{1}$, A.C. Fluck ${ }^{1}$, J.C. Gerei ${ }^{1}$, D. Col ${ }^{1}$, L. Berns ${ }^{1}$, \\ F. Hoffmann ${ }^{1}$, O.A.D. Costa ${ }^{2}$ \\ ${ }^{1}$ Universidade Tecnológica Federal do Paraná - Dois Vizinhos, PR \\ ${ }^{2}$ Universidade Federal de Pelotas - Pelotas, RS
}

\begin{abstract}
RESUMO
O objetivo do presente estudo foi avaliar o valor nutritivo do consórcio forrageiro entre gramíneas do gênero Cynodon (cv. tifton 85 ou coastcross) com Arachis pintoi (amendoim forrageiro). O experimento foi conduzido na Universidade Tecnológica Federal do Paraná, Câmpus Dois Vizinhos, em área de aproximadamente $3000 \mathrm{~m}^{2}$. O delineamento experimental foi de blocos ao acaso, com quatro tratamentos e três repetições. Os tratamentos foram: tifton 85 e coastcross em cultivo estreme, tifton $85+\mathrm{AF}$ e coastcross + AF. Foram avaliados os teores de PB, FDN, FDA, DIVMS, MM e MS das lâminas foliares, colmo+bainha, amendoim forrageiro e da MF disponível da simulação de pastejo. Foi observado que a coastcross tem menor teor de fibra, independentemente do tratamento. $\mathrm{O}$ avanço das estações do ano proporcionou menores valores de PB e DIVMS em todos os tratamentos. A simulação de pastejo demonstrou que a tifton 85 tem maiores teores de MS, assim como valores inferiores são encontrados para os consórcios. Quando consorciado com as gramíneas, o amendoim forrageiro reduziu os compostos fibrosos na pastagem, acrescentando maiores teores de PB em pastagem de gramíneas no final do ciclo produtivo.
\end{abstract}

Palavras-chave: composição química, componente proteico, componentes fibrosos, leguminosa

\begin{abstract}
The goal of this study was to evaluate the fodder performance and production of Cynodon (Cv. Tifton 85 or Coastcross) mixed with Arachis pintoi (Forage peanut). The experiment was conducted at the Universidade Tecnológica Federal do Paraná, Câmpus Dois Vizinhos, at an area of approximately $3000 \mathrm{~m}^{2}$. A completely randomized block design was applied, with four treatments and three replicates. The treatments were: Tifton 85 and Coastcross in pure crop, Tifton $85+$ AF and Coastcross + AF with rotated and successive implantation of one line to the grass and three consecutive lines to the legume. The content of $C P, N D F, A D F, I V D M D$ ashe and DM of the leaf blades, stem of grasses forage peanut and total forage mass available of grazing simulation was evaluated. Coastcross has lower fibrous contents, regardless of treatment. The changing of the seasons during the year provided lower values of $C P$ and IVDMD for all treatments. The evaluation of the grazing simulation showed that Tifton 85 has higher DM values just as the lower ones are found for consortia. When mixed with grasses, forage peanuts reduce the fibrous compounds on pasture, increasing the CP levels in grass pasture at the end of productive cycle.
\end{abstract}

Keywords: chemical composition, fibrous compound, protein compound, legume

\section{INTRODUÇÃO}

Na região Sul do país, uma das atividades que mais se destaca é a pecuária, utilizando gramíneas como base alimentar da produção

Recebido em 17 de maio de 2017

Aceito em 19 de fevereiro de 2018

E-mail: andreia_fiorelli@hotmail.com animal. A principal forma de uso dessas forrageiras é a implantação do modo convencional, ou seja, em cultivo exclusivo. Porém, o modo convencional, juntamente ao manejo de fertilidade do solo deficiente, acarretará pastagens de menor valor nutritivo e com produtividade inferior. 
Dentre as gramíneas empregadas, as do gênero Cynodon, em especial as cv. coastcross e tifton 85 , destacam-se pela capacidade de produzirem altas quantidades de forragem e terem elevada qualidade nutricional (Gonçalves et al., 2002). No entanto, elas necessitam da utilização de adubação nitrogenada para melhor resposta, ou seja, são verificados aumentos nos teores de proteína bruta $(\mathrm{PB})$ e digestibilidade (DIVMS), além da redução do percentual de fibra em detergente neutro (FDN) na massa de forragem, quando bem adubadas (Quaresma et al., 2011).

Portanto, a utilização da consorciação com outra espécie forrageira é considerada uma técnica sustentável, especialmente com leguminosas. Estas podem minimizar a aplicação de adubos nitrogenados, contribuindo para o equilíbrio da oferta e a qualidade da forragem no decorrer da utilização. $O$ principal fator do uso de leguminosas é a melhoria da produção animal em relação à pastagem de gramíneas em plantio singular, além da redução dos custos de produção (Assmann et al., 2004).

O amendoim forrageiro (Arachis pintoi) surge como opção para melhorar o sistema convencional, principalmente pela adaptação da espécie às condições climáticas da região Sul, mantendo seu valor nutritivo por um longo período (Nascimento et al., 2010). Essa leguminosa pode ser usada como banco de proteínas e recomendada na formação de pastagens consorciadas, pelo elevado valor nutritivo, estabelecendo-se bem com gramíneas agressivas como as do gênero Cynodon (Pizzani et al., 2010).

O estudo de pastagens do gênero Cynodon consorciadas com Arachis pintoi, desde a implantação até o decorrer da sua utilização para pastejo, pode contribuir de forma efetiva para resultados eficazes na produção de ruminantes. Assim, o objetivo deste estudo foi avaliar os efeitos da maior ocupação de área de amendoim forrageiro no estabelecimento de pastagens de coastcross e tifton 85 sobre o valor nutritivo dos seus componentes estruturais e da massa de forragem total, no decorrer do primeiro ano pósimplantação.

\section{MATERIAL E MÉTODOS}

O experimento foi conduzido na Universidade Tecnológica Federal do Paraná - Câmpus Dois Vizinhos, sudoeste do Paraná, no período de maio de 2015 a maio de 2016, aprovado e protocolado ( $\mathrm{n}^{\circ}$ 2015-30) pela Comissão de ética no uso de animais (CEUA) desta instituição. Foi desenvolvido em área experimental de aproximadamente $3000 \mathrm{~m}^{2}$, com 12 piquetes de $15 \mathrm{x} 15 \mathrm{~m}$. Utilizaram-se duas cultivares do gênero Cynodon (tifton 85 e coastcross) e uma leguminosa do gênero Arachis (amendoim forrageiro cv. Amarillo). Para a implantação da pastagem, foi feito o preparo convencional do solo e antecedendo a implantação, realizou-se o controle de plantas invasoras por meio de capina manual e dessecação.

Coletaram-se amostras de solo para análise química e posteriormente, foram feitas as recomendações de adubação de N-P-K, sendo usado o adubo químico na formulação 8-20-10, na quantidade de $550 \mathrm{~kg} \mathrm{ha}{ }^{-1}$. A cada dois pastejos, foi aplicada adubação de cobertura, com $20 \mathrm{~kg} \mathrm{ha}^{-1}$ de $\mathrm{N}$ na forma de ureia, totalizando $60 \mathrm{~kg} \mathrm{ha}^{-1}$ ao longo do ano agrícola. A introdução do amendoim forrageiro foi feita por meio de sementes puras e viáveis em maio de 2015, e as gramíneas introduzidas com mudas, em julho de 2015 quando o amendoim já estava preestabelecido na área. $\mathrm{O}$ espaçamento entre plantas foi de $50 \mathrm{~cm}$, com espaçamento entre linhas de $60 \mathrm{~cm}$.

O delineamento experimental foi em blocos ao acaso, com quatro tratamentos e três repetições: tifton 85 em cultivo estreme; coastcross em cultivo estreme; tifton $85+$ amendoim forrageiro e coastcross + amendoim forrageiro. Os consórcios foram feitos, de forma intercalada e sucessiva, de uma linha de gramínea e três linhas de leguminosas, disponibilizando $75 \%$ da área para o desenvolvimento do amendoim forrageiro, para cada sistema em consórcio.

O manejo de pastagem adotado foi $\mathrm{o}$ rotacionado, utilizando vacas lactantes da raça Jersey para o pastejo, com oferta de forragem de $5 \mathrm{~kg}$ MS para cada $100 \mathrm{~kg}$ de peso vivo. As amostragens foram realizadas nas semanas dos dias 30/11/2015; 14/12/2015; 05/01/2016; 27/01/2015; 29/02/2016; 28/03/2016 e 26/04/2016, totalizando sete pastejos. As coletas 
ocorreram em três pontos ao acaso, sendo esses pontos homogêneos no piquete. As amostras foram cortadas com auxílio de uma tesoura tipo martelo e com quadro de $0,25 \mathrm{~m}^{2}$. Também, foram coletadas amostras de simulação de pastejo, de acordo com a metodologia de Moore e Sollemberger (1997), sendo observado o comportamento dos animais, considerando-se a área, a altura e as partes das plantas que eram consumidas, a fim de se estabelecer amostragem mais próxima da selecionada pelos animais. As coletas foram feitas na entrada dos animais e, após meio período de consumo, realizou-se uma nova coleta, buscando a proporção de pastejo da planta mais adequada do total das horas de utilização desta pastagem pelos animais.

Para avaliação da composição bromatológica do dossel, foram utilizadas amostras da simulação de pastejo e frações botânicas/estruturais. Para isso, posteriormente aos cortes, à pesagem e à separação botânica/estrutural, as amostras foram pesadas e secas em estufa com circulação de ar forçada a $55^{\circ} \mathrm{C}$, até atingirem peso constante $(72$ horas), para a determinação da porcentagem de matéria parcialmente seca de cada componente. Em seguida, foram moídas em moinho tipo "Willey", com peneira de crivo de $1 \mathrm{~mm}$. Realizou-se análise composta por estação, assim, o material pertencente a cada pastejo efetuado dentro da mesma estação foi agrupado na mesma proporção para cada coleta, mantendo-se a individualização entre componentes a serem analisados.

Foram determinados os teores de matéria seca (MS) por secagem em estufa a $105^{\circ} \mathrm{C}$ durante oito horas e de cinzas por queima em mufla a $600^{\circ} \mathrm{C}$ durante quatro horas. O teor de nitrogênio total (N) foi determinado pelo método de Kjeldahl (método 984.13, AOAC, 1995), com solução padrão de ácido clorídrico para a titulação e então, verificou-se o valor de PB da amostra. Os teores de fibra em detergente neutro (FDN) e fibra em detergente ácido (FDA) foram determinados no equipamento Ankom (ANKOM $200 \circledR$ ), seguindo a metodologia descrita por Van Soest et al. (1991).

Para a estimativa da digestibilidade in vitro na matéria seca (DIVMS), foi utilizada a técnica descrita por Tilley e Terry (1963) modificada pela Ankom e inóculo ruminal, incubado a $39^{\circ} \mathrm{C}$ durante 48 horas, com agitação lenta, utilizando a incubadora (TE-150 Tecnal). Foi coletado líquido ruminal de bovino macho adulto da raça Holandesa, adaptado por sete dias ao consumo das forrageiras estudadas.

Os dados coletados foram submetidos a análises de variância pelo Proc. Mixed, e as médias comparadas $(\mathrm{P}<0,05)$ pelo teste de Tukey, assim como correlações lineares entre os componentes nutricionais e DIVMS foram estimadas para as amostras da simulação de pastejo, utilizando-se o SAS 9.0 (Statistical..., 2004).

\section{RESULTADOS E DISCUSSÃO}

Foi observada diferença significativa $(\mathrm{P}<0,05)$ para os teores de fibra em detergente neutro (FDN) e fibra em detergente ácido (FDA) na lâmina foliar (LF) (Tab. 1). O consórcio de tifton 85 + AF apresentou valor de FDN superior quando comparado ao coastcross + AF. Em ambos os consórcios, a porcentagem de FDN da LF não diferiu das gramíneas em cultivo estreme. Para a FDA das LF, a coastcross em cultivo estreme apresentou valor inferior aos demais pastos, os quais não diferiram entre si.

Apesar dos valores mais altos de FDN nas forrageiras tifton 85 , coastcross e nos consórcios, eles estão dentro da média geralmente registrada para gramíneas tropicais. Soares et al. (2009) afirmam que valores entre $70-73 \%$ de FDN são considerados aceitáveis em plantas forrageiras. Esses mesmos autores enfatizam a relação direta da FDN com o consumo pelo animal e da FDA com a digestibilidade da forragem. Ziech et al. (2015), ao estudarem duas cultivares de Cynodon, descreveram maior percentual de FDN na LF para a cv. tifton $85(73,02 \%)$, sendo $6,4 \%$ superior à coastcross.

Houve diferença $(\mathrm{P}<0,05)$ entre as estações do ano para todos os componentes nutricionais da LF. A primavera diferiu das demais estações, com o menor teor de MS e a maior MM. O acúmulo de MS aumentou com o tempo, como o esperado. Para os teores de MM, Ziech et al. (2015) verificaram, ao longo dos períodos, muita variação da MM nas frações estruturais do pasto, com pouca amplitude entre os valores, diferentemente deste estudo, que apresentou $8,15 \%$ para a primeira estação estudada. 
Tabela 1. Massa seca (MS), matéria mineral (MM), fibra em detergente neutro (FDN), fibra em detergente ácido (FDA), proteína bruta (PB) e digestibilidade in vitro na matéria seca (DIVMS) dos componentes estruturais: lâmina foliar (LF) e colmo+bainha (CB), de pastagens de coastcross e tifton 85 estabelecidas de forma singular ou em consórcio com o amendoim forrageiro, ao longo de três estações produtivas. Dois Vizinhos - PR, 2016

\begin{tabular}{|c|c|c|c|c|c|c|}
\hline Forrageiras & MS* & $\mathrm{MM}^{*}$ & FDN* & FDA* & PB* & DIVMS* \\
\hline \multicolumn{7}{|c|}{ LF (\%) } \\
\hline Coastcross & $26,66^{\mathrm{ns}}$ & $7,12^{\text {ns }}$ & $68,65^{\mathrm{ab}}$ & $27,05^{b}$ & $22,33^{\mathrm{ns}}$ & $56,75^{\mathrm{ns}}$ \\
\hline Tifton 85 & 27,99 & 7,21 & $69,19^{\mathrm{ab}}$ & $29,44^{\mathrm{a}}$ & 20,40 & 54,85 \\
\hline Coastcross $+\mathrm{AF}$ & 25,41 & 7,30 & $67,86^{\mathrm{b}}$ & $29,09^{\mathrm{a}}$ & 22,04 & 59,30 \\
\hline Tifton $85+\mathrm{AF}$ & 27,16 & 7,20 & $70,76^{\mathrm{a}}$ & $30,13^{\mathrm{a}}$ & 21,36 & 55,56 \\
\hline \multicolumn{7}{|l|}{ Estações do ano } \\
\hline Primavera & $23,28^{\mathrm{b}}$ & $8,15^{\mathrm{a}}$ & $65,50^{\mathrm{c}}$ & $28,02^{\mathrm{b}}$ & $23,93^{\mathrm{a}}$ & $57,91^{\mathrm{b}}$ \\
\hline Verão & $29,27^{\mathrm{a}}$ & $6,92^{\mathrm{b}}$ & $68,99^{\mathrm{b}}$ & $28,54^{\mathrm{b}}$ & $19,46^{\mathrm{c}}$ & $63,50^{\mathrm{a}}$ \\
\hline Outono & $27,88^{\mathrm{a}}$ & $6,57^{\mathrm{b}}$ & $72,85^{\mathrm{a}}$ & $30,23^{\mathrm{a}}$ & $21,21^{\mathrm{b}}$ & $48,44^{\mathrm{c}}$ \\
\hline $\mathrm{CV}(\%)$ & 10,92 & 7,21 & 2.94 & 2,30 & 6,90 & 9,01 \\
\hline $\mathrm{R}^{2}$ & 0,65 & 0,77 & 0,81 & 0,82 & 0,76 & 0,77 \\
\hline \multicolumn{7}{|l|}{ CB (\%) } \\
\hline Coastcross & $20,62^{b}$ & $7,82^{\mathrm{ns}}$ & $74,40^{\mathrm{ns}}$ & $35,18^{b}$ & $14,16^{\mathrm{ns}}$ & $50,33^{\mathrm{ns}}$ \\
\hline Tifton 85 & $24,14^{\mathrm{a}}$ & 7,76 & 75,94 & $37,27^{\mathrm{a}}$ & 12,76 & 48,95 \\
\hline Coastcross $+\mathrm{AF}$ & $19,37^{\mathrm{b}}$ & 7,56 & 74,03 & $37,15^{\mathrm{ab}}$ & 12,06 & 49,70 \\
\hline Tifton $85+\mathrm{AF}$ & $21,74^{\mathrm{ab}}$ & 7,80 & 76,10 & $37,57^{\mathrm{a}}$ & 12,02 & 43,11 \\
\hline \multicolumn{7}{|l|}{ Estações do ano } \\
\hline Primavera & $18,05^{\mathrm{b}}$ & $9,35^{\mathrm{a}}$ & $71,55^{\mathrm{b}}$ & $34,47^{\mathrm{b}}$ & $15,39^{\mathrm{a}}$ & $53,99^{\mathrm{a}}$ \\
\hline Verão & $23,55^{\mathrm{a}}$ & $7,05^{\mathrm{b}}$ & $76,17^{\mathrm{a}}$ & $37,79^{\mathrm{a}}$ & $12,12^{\mathrm{b}}$ & $53,98^{\mathrm{a}}$ \\
\hline Outono & $22,81^{\mathrm{a}}$ & $6,81^{\mathrm{b}}$ & $77,63^{\mathrm{a}}$ & $38,13^{\mathrm{a}}$ & $10,74^{\mathrm{b}}$ & $39,84^{\mathrm{b}}$ \\
\hline $\mathrm{CV}(\%)$ & 11,69 & 6,69 & 2,31 & 3,98 & 17,18 & 11,29 \\
\hline $\mathrm{R}^{2}$ & 0,74 & 0,89 & 0,82 & 0,77 & 0,68 & 0,77 \\
\hline
\end{tabular}

Letras distintas minúsculas nas colunas diferem entre si pelo teste de Tukey a $5 \%$ de significância $(\mathrm{P}<0,05)$. Ns $=$ não significativo. $\mathrm{CV}=$ coeficiente de variação.

* Em porcentagem da matéria seca.

Para os valores de FDN e FDA, a diferença foi maior ao longo das estações, sendo no outono a maior concentração de fibra, devido ao avançar do estágio fenológico das folhas destas plantas, assim como relatado por Pellegrini et al. (2016), os quais evidenciam que o teor elevado de FDN para as folhas no inverno se deve à maturação fisiológica da planta, reflexo da diminuição do fotoperíodo e da temperatura, bem como ao acúmulo de material senescente oriundo da concentração de forragem no período.

O teor de FDN aumentou 7,35 pontos percentuais da primavera ao outono, variando entre 65,6 e $72,85 \%$. Valores similares foram relatados por Barbero et al. (2010), para LF de coastcross consorciada com amendoim forrageiro com aplicação de $100 \mathrm{~kg} \mathrm{ha}^{-1}$ ano de $\mathrm{N}$, valores de 67,$9 ; 68,6$ e $67,4 \%$ de FDN, para primavera, verão e outono, respectivamente; assim, apenas para o outono esses autores encontraram menor teor que no presente trabalho.
Para os teores de $\mathrm{PB}$, a maior porcentagem nas LF foi encontrada na primavera; esse maior percentual de $\mathrm{PB}$ para essa estação é devido à maior relação folha:colmo em plantas jovens, sendo justamente as folhas as responsáveis pelo maior acúmulo de PB das plantas (Taiz e Zeiger, 1991). Barbero et al. (2010), em pastejo de lotação contínua, não observaram diferença entre as épocas do ano, o que mostra que a constante remoção foi compensada com a formação de folhas novas.

Foi observada maior DIVMS das LF no verão, diferindo $(\mathrm{P}<0,05)$ das demais estações, com a menor DIVMS no outono, devido à maior concentração de fibra, indicada pelos resultados da FDA. Barbero et al. (2010) encontraram para a DIVMS das LF valores mais elevados para o período do verão, propiciando à pastagem melhores condições. A qualidade dos alimentos é geralmente medida pelo seu valor alimentar, e a digestibilidade é um dos constituintes. O maior 
valor de DIVMS indica a proporção do alimento que está disponível para ser utilizado pelo animal.

O colmo+bainha (CB) apresentou diferença significativa $(\mathrm{P}<0,05)$ apenas para as variáveis MS e FDA. A gramínea tifton 85 apresentou maior teor de MS para CB quando cultivada solteira ou em consórcio com o amendoim, diferindo da cv. coastcross. Esse maior percentual de MS da tifton 85 é devido ao alongamento intensificado do colmo, constatado por Oliveira et al. (2000), que, ao avaliarem idades de rebrota da tifton 85 , observaram que os teores de MS na fração colmo aumentaram linearmente com a idade $(21,9 ; 26,9 ; 27,0 \%$ de MS para as idades de rebrota de 42; 49; 56 dias). Valores inferiores de FDA foram observados no $\mathrm{CB}$ na pastagem de coastcross solteira ou quando consorciada com a leguminosa. Contudo, o menor valor para FDA do colmo na cv. coastcross pode estar relacionado a sua característica estrutural, como ressaltado por Oliveira et al. (2011), os quais citam que o colmo do capim coastcross tem diâmetro reduzido, se comparado a algumas gramíneas.

Nas estações do ano avaliadas, houve diferença significativa $(\mathrm{P}<0,05)$ para o constituinte $\mathrm{CB}$. Os valores de MS, FDN e FDA foram aumentando para as estações verão e outono, as quais diferiram da primavera, que apresentou os menores valores esperados para gramíneas desse gênero. Os maiores teores de FDA para o verão e o outono indicam maiores concentrações de celulose e lignina, dada sua característica de sustentação (Taiz e Zeiger, 1991). Uma menor concentração de FDN e FDA no colmo na primavera também foi relatada por Branco et al. (2012), com valores entre 70,36 e 37,02\%, respectivamente, sendo esse valor de FDA superior ao encontrado neste estudo.

Os teores de $\mathrm{MM}$ e $\mathrm{PB}$ do $\mathrm{CB}$ na primavera apresentaram os maiores valores, 9,35\% $\mathrm{MM}$ e $15,39 \%$ de PB. A diferença da PB para CB do outono/inverno para a primavera é ocasionada pela diminuição do pastejo, devido ao aumento da seleção animal, consequentemente, os colmos ficam velhos, reduzindo o teor de PB, além do declínio normal que ocorre pelo envelhecimento da planta.

A DIVMS foi superior na primavera e no verão, diferindo do outono, quando apresentou uma queda acentuada de 15 pontos percentuais na estação final do ciclo produtivo. A diminuição na DIVMS ao longo das estações pode estar ligada a um possível déficit de $\mathrm{N}$ nas pastagens (Ziech et $a l ., 2015)$. Estes autores observaram redução na DIVMS do $\mathrm{CB}$, entre a primeira e a última estação avaliada, de $25,4 \%$. As maiores mudanças na composição das plantas forrageiras são decorrentes da sua maturidade, pelo declínio do seu valor nutritivo com o avanço do ciclo vegetativo (Andrade et al., 2007).

A composição bromatológica do amendoim forrageiro nos consórcios é alterada significativamente $(\mathrm{P}<0,05)$ apenas para a FDA (Tab. 2). $\mathrm{O}$ consórcio da tifton 85+AF apresentou o maior teor, quando comparado ao consórcio com a coastcross. Essa diferença pode ser proporcionada pelo maior sombreamento que a cv. tifton 85 ocasiona na leguminosa, devido à maior quantidade de massa quando comparada à coastcross. Gobbi et al. (2010), ao estudarem o efeito do sombreamento no amendoim, observaram o aumento linear da FDA com os níveis crescentes de sombra, em média 13 e 16\%, sob os níveis de 50 e $70 \%$ de sombra, em relação ao tratamento em pleno sol. Os valores encontrados são similares aos resultados desses autores, que descrevem valores de 28,0;32,8 e $33,8 \%$ de FDA para $0 ; 50$ e $70 \%$ de sombreamento.

Para as estações do ano, a porcentagem de MS do amendoim é maior no outono, diferindo das estações primavera e verão, e a MM decresce com o passar das estações $(\mathrm{P}<0,05)$. Os valores de MS e MM encontrados são inferiores para MS e similares à MM de Ferreira et al. (2012), quando estudaram diferentes acessos do amendoim forrageiro e obtiveram valores médios de MS e MM variando de 22,1 a 29,1 e de 8,9 a $13,6 \%$, respectivamente.

Os teores de FDN e FDA foram crescentes com o avanço da estação; já o outono diferiu das demais estações em grande proporção, visto que, com o passar do ciclo, ocorre maior deposição de carboidratos estruturais na parede celular da planta (Oliveira et al., 2013). A DIVMS teve seu menor valor para a última estação estudada, diferindo significativamente $\quad(\mathrm{P}<0,05) \quad$ da primavera e do verão, quando ocorreram maiores DIVMS do amendoim, seguindo a mesma 
relação dos teores de fibra: quanto maior a porcentagem de fibra, menor a digestibilidade.

Tabela 2. Massa seca (MS), matéria mineral (MM), fibra em detergente neutro (FDN), fibra em detergente ácido (FDA), proteína bruta (PB) e digestibilidade in vitro na matéria seca (DIVMS) do amendoim forrageiro em consórcio com pastagens de coastcross e tifton 85 ao longo de três estações produtivas. Dois Vizinhos - PR, 2016

\begin{tabular}{lcccccc}
\multicolumn{1}{c}{ Forrageiras } & \multicolumn{5}{c}{ Amendoim } \\
\cline { 2 - 6 } & MS* & MM $^{*}$ & FDN $^{*}$ & FDA $^{*}$ & PB $^{*}$ & DIVMS $^{\text {ns }}$ \\
\hline Coastcross+AF & $15,07^{\mathrm{ns}}$ & $10,39^{\mathrm{ns}}$ & $48,77^{\mathrm{ns}}$ & $29,31^{\mathrm{b}}$ & $22,57^{\mathrm{ns}}$ & $63,09^{\mathrm{ns}}$ \\
Tifton 85+AF & 16,05 & 10,69 & 50,87 & $31,09^{\mathrm{a}}$ & 20,92 & 62,61 \\
Estações do ano & & & & & & \\
Primavera & $13,13^{\mathrm{b}}$ & $11,27^{\mathrm{a}}$ & $39,13^{\mathrm{c}}$ & $28,26^{\mathrm{b}}$ & $22,30^{\mathrm{ns}}$ & $62,46^{\mathrm{a}}$ \\
Verão & $15,03^{\mathrm{b}}$ & $10,64^{\mathrm{b}}$ & $46,67^{\mathrm{b}}$ & $28,92^{\mathrm{b}}$ & 22,44 & $69,99^{\mathrm{a}}$ \\
Outono & $18,52^{\mathrm{a}}$ & $9,72^{\mathrm{c}}$ & $63,66^{\mathrm{a}}$ & $33,42^{\mathrm{a}}$ & 20,50 & $53,09^{\mathrm{b}}$ \\
CV $(\%)$ & 12,03 & 3,81 & 9,22 & 10,46 & 10,46 & 8,15 \\
\hline
\end{tabular}

Letras distintas minúsculas nas colunas diferem entre si pelo teste de Tukey a $5 \%$ de significância $(\mathrm{P}<0,05)$. Ns $=$ não significativo. $\mathrm{CV}=$ coeficiente de variação. ${ }^{*}$ Em percentagem da matéria seca.

Para as avaliações na simulação de pastejo, foram verificadas diferenças significativas $(\mathrm{P}<0,05)$ para os constituintes MS, MM e FDN (Tab. 3). A cultivar tifton 85 apresentou maior valor de MS que as demais pastagens avaliadas, assim como valores inferiores observados nos consórcios com a leguminosa. A maior proporção de MS dessa cultivar está relacionada à sua característica estrutural e à proporção de colmo na biomassa.

Para a MM, houve diferença $(\mathrm{P}<0,05)$ das gramíneas solteiras quando consorciadas com o $\mathrm{AF}$, tendo o consórcio apresentado maiores valores de MM. Esse resultado foi maior para o consórcio porque o AF possui maior teor de MM. Valadares Filho et al. (2006) descrevem valores de 7,90 e 8,79\% de MM para pastagem e feno de amendoim forrageiro, dessa forma, quando em consórcio, a maior quantidade da leguminosa na composta influenciou a elevação desse teor.

O teor de FDN também apresentou diferença quando as gramíneas foram consorciadas, sendo reduzido, em média, 12,88\% o valor de FDN no consórcio com a leguminosa, não se distinguindo entre as espécies de gramíneas em questão. Essa diferença é devido à menor proporção de fibra nesta leguminosa, como apresentado na Tab. 2, a qual obteve, em média, 49,72\% de FDN. A inclusão do amendoim em $75 \%$ da área propiciou ao consórcio a redução nos teores de FDN.

Tabela 3. Massa seca (MS), matéria mineral (MM), fibra em detergente neutro (FDN) e digestibilidade bruta na matéria seca (DIVMS) da simulação de pastejo, em pastagens de coastcross e tifton 85 estabelecidas de forma singular ou em consórcio com o amendoim forrageiro, ao longo de três estações produtivas. Dois Vizinhos - PR, 2016

\begin{tabular}{lcccc}
\multicolumn{1}{c}{ Tratamentos } & MS $^{*}$ & MM $^{*}$ & FDN $^{*}$ & DIVMS $^{*}$ \\
\hline Coastcross & $23,60^{\mathrm{ab}}$ & $7,21^{\mathrm{b}}$ & $66,79^{\mathrm{a}}$ & $65,35^{\mathrm{ns}}$ \\
Tifton 85 & $26,39^{\mathrm{a}}$ & $6,92^{\mathrm{b}}$ & $68,35^{\mathrm{a}}$ & 63,65 \\
Coastcross+AF & $19,79^{\mathrm{c}}$ & $8,19^{\mathrm{a}}$ & $59,28^{\mathrm{b}}$ & 65,64 \\
Tifton+AF & $21,57^{\mathrm{bc}}$ & $8,53^{\mathrm{a}}$ & $60,43^{\mathrm{b}}$ & 65,50 \\
Estações & & & & \\
Primavera & $19,24^{\mathrm{b}}$ & $9,16^{\mathrm{a}}$ & $57,25^{\mathrm{c}}$ & $74,34^{\mathrm{a}}$ \\
Verão & $24,84^{\mathrm{a}}$ & $7,25^{\mathrm{b}}$ & $64,06^{\mathrm{b}}$ & $65,06^{\mathrm{b}}$ \\
Outono & $24,43^{\mathrm{a}}$ & $6,72^{\mathrm{b}}$ & $69,83^{\mathrm{a}}$ & $55,71^{\mathrm{c}}$ \\
\hline CV $(\%)$ & 10,79 & 9,41 & 3,62 & 3,91 \\
$\mathrm{R}^{2}$ & 0,81 & 0,86 & 0,94 & 0,94 \\
\hline
\end{tabular}

Letras distintas minúsculas nas colunas diferem entre si pelo teste de Tukey a $5 \%$ de significância $(\mathrm{P}<0,05)$. Ns $=$ não significativo. $\mathrm{CV}=$ coeficiente de variação.*Porcentagem da matéria seca. 
Para a DIVMS, não foi observada diferença significativa entre as espécies estudadas. Porém, foram verificadas correlações significativas $(\mathrm{P}<0,05)$ da DIVMS com quase todos os nutrientes avaliados, entre as espécies, na simulação de pastejo. No consórcio coastcross+AF, houve correlação entre todos os componentes, (MS -0,91; MM 0,92; PB 0,81; FDN -0,94; FDA -0,97), o que agrega melhor digestibilidade. Para os outros tratamentos, as correlações mantêm o mesmo padrão, negativas para MS, FDN, FDA e positivas para os constituintes MM, PB. A correlação negativa que mais se evidencia é encontrada entre FDA e DIVMS nos consórcios, valores de $-0,97$ $(\mathrm{P}<0,001)$ para a coastcross $+\mathrm{AF}$ e de $-0,96$ $(\mathrm{P}<0,001)$ para a tifton+AF. Esse fato ocorre em razão de a composição da parede celular ser constituída por fração indigestível, sendo responsável pela diminuição da DIVMS dos carboidratos fibrosos.

Ao se analisar a PB e a FDA na simulação de pastejo, verificou-se interação significativa $(\mathrm{P}<0,05)$ entre cultivares e estações (Tab. 4). Foi observado maior teor de $\mathrm{PB}$ para o consórcio de coastcross+AF na primavera, com $23,75 \%$. A cv. tifton 85 apresentou o menor teor de PB comparada aos demais tratamentos no outono. $\mathrm{Na}$ estação mais quente do ano, o verão, a diferença ocorreu apenas entre a tifton 85 e o consórcio forrageiro da coastcross $+\mathrm{AF}$. Diferenças no teor de PB entre essas cultivares também foram observadas por Ziech et al. (2015), os quais encontraram 18,$60 ; 16,82 \%$ para a cv. coastcross e a tifton 85 , respectivamente, no período da primavera.

Tabela 4. Médias da interação entre os tratamentos e as estações, para proteína bruta (PB) e fibra em detergente ácido (FDA) da simulação de pastejo, em pastagens de coastcross e tifton 85 estabelecidas de forma singular ou em consórcio com o amendoim forrageiro (AF), ao longo de três estações produtivas do ano. Dois Vizinhos - PR, 2016.

\begin{tabular}{lccc}
\hline & Primavera & Verão & Outono \\
\cline { 2 - 4 } \multicolumn{1}{c}{ Tratamentos } & & PB $(\%)$ & $18,10^{\mathrm{Ba}}$ \\
Coastcross & $20,07^{\mathrm{Ab}}$ & $16,30^{\mathrm{Cab}}$ & $15,13^{\mathrm{Bb}}$ \\
Tifton 85 & $19,97^{\mathrm{Ab}}$ & $14,79^{\mathrm{Bb}}$ & $17,35^{\mathrm{Ba}}$ \\
Coastcross+AF. & $23,75^{\mathrm{Aa}}$ & $17,37^{\mathrm{Ba}}$ & $17,34^{\mathrm{Ba}}$ \\
Tifton 85+AF & $19,99^{\mathrm{Ab}}$ & $16,05^{\mathrm{Bab}}$ & 16,96 \\
Média & 20,94 & 16,13 & \\
Tratamentos & & $\mathrm{FDA}(\%)$ & $31,46^{\mathrm{Ab}}$ \\
Coastcross & $26,70^{\mathrm{Ba}}$ & $31,40^{\mathrm{Aa}}$ & $33,47^{\mathrm{Aa}}$ \\
Tifton 85 & $26,17^{\mathrm{Cab}}$ & $30,99^{\mathrm{Bab}}$ & $31,93^{\mathrm{Aab}}$ \\
Coastcross+AF & $24,75^{\mathrm{Cb}}$ & $28,11^{\mathrm{Bc}}$ & $32,26^{\mathrm{Aab}}$ \\
Tifton 85+AF & $25,74^{\mathrm{Cab}}$ & $29,13^{\mathrm{Bbc}}$ & 32,28 \\
Média & 25,84 & 29,91 & \\
\hline Letras distintas maiúsculas na linha e minúsculas nas colunas entre cada variável diferem entre si pelo teste de Tukey \\
a 5\% de significância $(\mathrm{P}<0,05)$. Ns= não significativo. & &
\end{tabular}

Comparando as estações do ano, foi constatado que a primavera propiciou os maiores teores de $\mathrm{PB}$, o que está relacionado ao estágio dessas plantas, além da maior proporção de lâminas foliares que plantas jovens apresentam, elevando os teores proteicos do pasto, em relação às duas estações posteriores. As estações do outono e inverno apresentaram teores similares para esse componente nutricional.

Para os teores de FDA das forragens (Tab. 4), foi observado efeito oposto aos valores encontrados de PB, tendo as maiores concentrações de FDA resultado em menores teores de $\mathrm{PB}$, como considerado anteriormente. Há uma relação inversa entre o aumento na concentração de componentes da parede celular, como a celulose, a hemicelulose, a lignina, e o conteúdo celular, representado por proteína e carboidratos solúveis (Pereira e Reis, 2001), evidenciada pelos valores encontrados de correlação significativa $(\mathrm{P}<0,05)$ entre a PB e a FDA para todas as espécies estudadas, em cultivo singular ou no consórcio, ou seja, valores de correlação negativa $(-0,70$ a $0,86)$.

O consórcio de coastcross+AF teve o menor teor de FDA em relação à gramínea em cultivo 
estreme na estação da primavera. No verão, os consórcios com o amendoim forrageiro denotaram teores inferiores de FDA, demonstrando $\mathrm{o}$ benefício do amendoim forrageiro no sistema. No período do outono, houve diferença entre as gramíneas em cultivo estreme, na qual, a tifton 85 apresentou o maior teor de FDA que a coastcross. Esse resultado é semelhante ao de Moreira et al. (2006), que encontraram valores superiores de FDA $(38,3$ a $43,7 \%$ ) para a tifton 85 , avaliados em diferentes períodos de crescimento. Esses autores justificam o fato pelas mudanças estruturais na parede celular no decorrer das estações devido à alteração de temperatura. Tal variação também pode ser atribuída aos fatores estruturais de sustentação da planta durante o seu desenvolvimento.

O teor de FDA foi crescente com o passar das estações. A primavera apresentou o menor teor para todas as espécies forrageiras estudadas, diferenciando-se dos demais períodos. Já no outono foram constatados teores de FDA superiores para todos os tratamentos, com média de $32,28 \%$, exceto para a coastcross em cultivo estreme, que permaneceu com o mesmo teor do verão. Devido aos fatores climáticos, de temperaturas desfavoráveis para essas gramíneas no outono, prejudicando o crescimento vegetativo, refletindo na formação de novos perfilhos, o que comprometeu a qualidade da forragem, pois ela é dependente das condições intrínsecas da planta e extrínsecas, como temperatura, luminosidade, umidade e nutrição mineral (Confortin et al., 2010).

\section{CONCLUSÃO}

A cv. coastcross obteve menores teores de fibra, independentemente do tipo de cultivo. O amendoim forrageiro tem o maior teor de FDA quando consorciado à cv. tifton 85. Há um declínio da qualidade nutricional com o avanço das estações do ano, devido ao aumento dos teores fibrosos e à diminuição do conteúdo proteico. A avaliação da simulação de pastejo evidenciou que, quando consorciado com as gramíneas, o amendoim forrageiro promove redução dos componentes fibrosos do dossel e propicia maiores teores de $\mathrm{PB}$ em pastagem de gramíneas em final de ciclo produtivo.

\section{REFERÊNCIAS}

ANDRADE, R.L.R.; RODRIGUES, T.J.D.; REIS, R.A. et al. Produção de massa seca e composição química de cinco cultivares de Cynodon. Acta Sci. Anim. Sci., v.28, p.251-258, 2007.

ASSMANN, A.L.; PELISSANI, A.; MORAES, A.D. et al. Produção de gado de corte e acúmulo de matéria seca em sistemas de integração lavoura-pecuária em presença e ausência de trevo branco e nitrogênio. Rev. Bras. Zootec., v.33, p.37-47, 2004.

ASSOCIATION OF OFFICIAL ANALYTICAL CHEMISTS. Official methods of analysis. $12 \mathrm{ed}$. Washington, D.C. 1995.

BARBERO, L.M.; CECATO. U.; LUGÃO, S.M.B. et al. Produção animal e valor nutritivo da forragem de pastagem de coastcross consorciada com amendoim forrageiro. Arq. Bras. Med. Vet. Zootec., v.62, p.645-653, 2010.

BRANCO, A.F.; VIANA, K.B.; CASTAÑEDA, R.D. et al. Chemical composition and crude protein fractions of Coastcross grass under grazing on winter, spring and summer in Southern Brazil. Acta Sci. Anim. Sci., v.34, p.183-187, 2012.

CONFORTIN, A.C.C.; QUADROS, F.L.F.; ROCHA, M.G. et al. Morfogênese e estrutura de azevém anual submetido a três intensidades de pastejo. Acta Sci. Zootec., v.32, p.385-391, 2010.

FERREIRA, A.L.; MAURÍCIO, R.M.; PEREIRA, L.G.R. et al. Nutritional divergence in genotypes of forage peanut. Rev. Bras. Zootec., v.41, p.856-863, 2012.

GOBBI, K.F.; GARCIA, R.; GARCEZ NETO, A.F. et al. Valor nutritivo do capim-braquiária e do amendoim forrageiro submetidos ao sombreamento. Arch. Zootec., v.59, p.379-390, 2010.

GONÇALVEZ, G.D.; SANTOS, G.T.; CECATO, U. et al. Produção e valor nutritivo de gramíneas do gênero Cynodon em diferentes idades ao corte durante o ano. Acta Sci. Anim. Sci., v.24, p.1163-1174, 2002. 
MOORE, J.E.; SOLLEMBERGER, L.E. Techniques to predict pasture intake. In: SIMPÓSIO INTERNACIONAL SOBRE PRODUÇÃO ANIMAL SOB PASTEJO, 1997, Viçosa. Anais... Viçosa: UFV, 1997. p.81-96.

MOREIRA, A.L.; REIS, A.R.; SIMILI, F.F. et al. Época de sobressemeadura de gramíneas anuais de inverno e de verão no capim-tifton 85: valor nutritivo. Ciênc. Agrotéc., v.30, p.335-343, 2006.

NASCIMENTO, I.S.; MONKS, P.L.; COELHO, R.W. et al. Aspectos qualitativos de forragem de amendoim forrrageiro cv. Alqueire-1 sob manejo de corte e adubação PK. Rev. Bras. Agric., v.16, p.117-123, 2010.

OLIVEIRA, E.R.; MONÇÃO. F.P.; GORDIN, C.L. et al. Degradação ruminal da fibra em detergente neutro de gramíneas do gênero Cynodon spp em quatro idades de corte. Rev. Agrar., v.6, p.205-214, 2013.

OLIVEIRA, M.A.; PEREIRA, O.G.; GARCIA, R. et al. Rendimento e valor nutritivo do capimtifton 85 (cynodon spp.) em diferentes idades de rebrota. Rev. Bras. Zootec., v.29, p.1949-1960, 2000.

OLIVEIRA, M.A.; PEREIRA, O.G.; RIBEIRO, K.G. et al. Produção e valor nutritivo do capimcoastcross sob doses de nitrogênio e idades de rebrotação. Arq. Bras. Med. Vet. Zootec., v.63, p.694-703, 2011.

PELLEGRINI, C.B.; MEDEIROS, R.B.; CARLOTTO, S.B. et al. Valor nutritivo de uma pastagem nativa dominada por eragrostis plana nees e sua relação com o perfil metabólico de vacas primíparas suplementadas da gestação ao pós-parto. Ciênc. Anim. Bras., v.17, p.154-163, 2016.

PEREIRA, J.R.; REIS, R.A. Produção de silagem pré-secada com forrageiras temperadas e tropicais. In: SIMPÓSIO SOBRE PRODUÇÃO E UTILIZAÇÃO DE FORRAGENS CONSERVADAS, 2001, Maringá. Anais... Maringá: UEM/CCA/DZO, 2001. p.139.
PIZANNI, R.; LOVATO, T.; QUADROS, F.L.F. Amendoim forrageiro (Arachis pintoi): uma alternativa sustentável para sistemas pecuários, In: MARTIN, T.N.; WACLAWOVSKY, A.J.; KUSS, F.; MENDES, A.S.; BRUN, E.J. (Orgs.). Sistemas de produção agropecuária (Ciências Agrárias, Animais e Florestais) - dois vizinhos, [Santa Cruz]: UTFPR, 2010. p.68-88.

QUARESMA, J.P.S.; ALMEIDA, R.G.; ABREU, J.G. et al. Produção e composição bromatológica do capim-tifton 85 (cynodon spp.) submetido a doses de nitrogênio. Acta Sci. Anim. Sci., v.33, p.145-150, 2011.

SOARES, A.B.; SARTOR L.R.; ADAMI, P.F. et al. Influência da luminosidade no comportamento de onze espécies forrageiras perenes de verão. Rev. Bras. Zootec., v.38, p.443-451, 2009.

STATISTICAL analysis system. Version 9.0. Cary: SAS Institute, 2004. 5135p.

TAIZ, L.; ZEIGER, E. Plant physiology. Califórnia: The Benjamin/Cummings Publishings Company, 1991. 565p.

TILLEY, J.M.A.; TERRY, R.A. A two-stage technique for the "in vitro" digestion of forage crops. J. Br. Grassl. Soc., v.18, p.104-111, 1963.

VALADARES FILHO, S.C.; MAGALHÃES, K.A.; ROCHA JÚNIOR, V.R.R. et al. Tabelas brasileiras de composição de alimentos para bovinos. CQBAL 2.0. 2.ed. Viçosa: UFV, 2006. $329 \mathrm{p}$.

VAN SOEST, P.J.; ROBERTSON, J.B.; LEWIS, B.A. Methods for dietary fiber, neutral detergent fiber, and nonstarch polysaccharides in relation to animal nutrition. J. Dairy Sci., v.74, p.35833597, 1991.

ZIECH, M.F.; OLIVO, J.C.; ZIECH, A.R.D. et $a l$. Nutritive value of pastures of Cynodon mixed with forage peanut in southwestern Paraná State. Acta Sci. Anim. Sci., v.37, p.243-249, 2015. 